\title{
Machining and Tool Wear Mechanisms during Machining Titanium Alloys
}

\author{
Alokesh Pramanik ${ }^{1, a}$, M.N. Islam ${ }^{1, b}$, Animesh Basak ${ }^{2, c}$ and Guy Littlefair ${ }^{3, d}$ \\ ${ }^{1}$ Department of Mechanical Engineering, Curtin University, Bentley, WA, Australia \\ ${ }^{2}$ Center for Advanced Microscopy, Australian National University, Canberra ACT 0200 Australia \\ ${ }^{3}$ School of Engineering, Deakin University, Waurn Ponds, Australia \\ aalokesh.pramanik@curtin.edu.au, bm.n.islam@curtin.edu.au canimesh.basak@anu.edu.au, \\ dguy.littlefair@deakin.edu.au
}

Keywords: Titanium alloys, machining mechanism, tool wear mechanism.

\begin{abstract}
This paper investigates the machining mechanism of titanium alloys and analyses those understandings systematically to give a solid understanding with latest developments on machining of titanium alloys. The chip formation mechanism and wear of different cutting tools have been analyzed thoroughly based on the available literature. It is found that the deformation mechanism during machining of titanium alloys is complex and it takes place through several processes. Abrasion, attrition, diffusion-dissolution, thermal crack and plastic deformation are main tool wear mechanisms.
\end{abstract}

\section{Introduction}

Titanium alloys are the most important and widely used metallic alloys in the aerospace industries $[1,2]$. However, those are difficult-to-machine materials because of (i) low thermal conductivity and volume specific heat of these materials result in high cutting temperature during machining, (ii) capacity to maintain strength at high temperature and severe work hardening ability lead to high machining forces and (iii) the ability to change phase of titanium alloys makes the deformation process more complex. Most of the harder tools, available in the market are not suitable to machine these materials due to chemical affinity which causes chemical wear in the cutting tool. Furthermore, chips weld easily on the tool to form built-up edge (BUE). As a result, cutting tool wears rapidly through different wear mechanism during machining.

Significant researches on machining titanium alloys have been performed to understand machining mechanism and enhance the tool life [3,4]. The deformation process of titanium alloys is very different to that of commonly used materials, such as aluminum, steel, etc. Under machining condition (high temperature, strain rate and strain) titanium alloys goes through different types of deformation depending on the machining parameters. Stress, temperature and vibration in the machining zone are the three main factors that enhance the cutting tool damage [5]. Tool wear, surface integrity and productivity are correlated and depend on the cutting parameters, such as, depth-of-cut, speed, feed, presence of coolant, cutting tool materials, etc. [6]. Researchers are continually engaged to improve the machinability of titanium alloys. Though there have been huge investigations in machining of these materials the results of those investigations are not well linked. In addition, a solid understanding of latest developments in chip formation and tool wear mechanisms is completely missing. This paper clearly identifies and explains those mechanisms which are imperatively needed to improve productivity of titanium alloys machining.

\section{Machining Mechanism}

Titanium alloys have a high yield stress to tensile strength ratio $(>0.9)$, and the flow stress increases dramatically with strain rate when strain rate is greater than $10^{3} \mathrm{~s}^{-1}$ [7-9] which is easily achieved in any machining process. Twin-dislocation interactions significantly influence strain hardening during deformation of titanium alloys though the dislocation motion accounted for the 
majority of plastic deformation [7]. Thus, high temperature strength, very low thermal conductivity, relatively low modulus of elasticity, high strain hardening, poor dislocation motion through the microstructure and high chemical reactivity play important roles in machining mechanism of these alloys [10]. Segmentation (normally known as saw-tooth chip) is a characteristic shape of the chip when machining titanium alloys $[11,12]$. This chip type is distinctly different to the 'continuous' or 'uniform-shear' chip which is formed during the machining of titanium alloys under conventional/low speed cutting conditions [13]. The mechanism of saw-tooth chip formation in machining titanium alloys is due to occurrence of thermo-plastic instability within the primary shear zone $[14,15]$. There are two important stages [16], such as, (1) segment formation involves upsetting of the wedge shaped volume of material immediately ahead of the tool and (2) accommodation of the further shear strain within the 'failed' shear zone which causes thermo-plastic instability. It involves gradual build-up of the segment with negligible deformation by the crushing work material ahead of the advancing crushing. The contact time between the segment being formed and the most advanced point of cutting edge is very short. With the advancement of crushing the contact increases and relative motion between the bottom surface of the chip segment being formed and the tool face is almost absent until the end of the segment formation stage. With the advancement of the cutting tool the new chip segment slowly pushes the previously formed chip segment. This builds-up stresses which cause extreme shear between the segments in the primary zone. At this stage, the concentrated shear bands are observed between the segments in a longitudinal midsection of a titanium chip [17].

Fig. 1 presents the morphology of the chip produced by milling of Ti-6Al4V [18]. Line A-B is the cross-section of the original undeformed surface and its length is characterised by L. The slipping angle $(\theta)$ is defined as the angle between the shear band and the tangent of the machined surface at the end of the shear band. Severe plastic deformation that occurred in a very narrow region is marked by C [18]. All the chips that are obtained show a segmented morphology [10]. As reported by several authors, such as, Ezugwu et al., [11, 12], segmentation is a characteristic shape of the chip when machining titanium alloys.

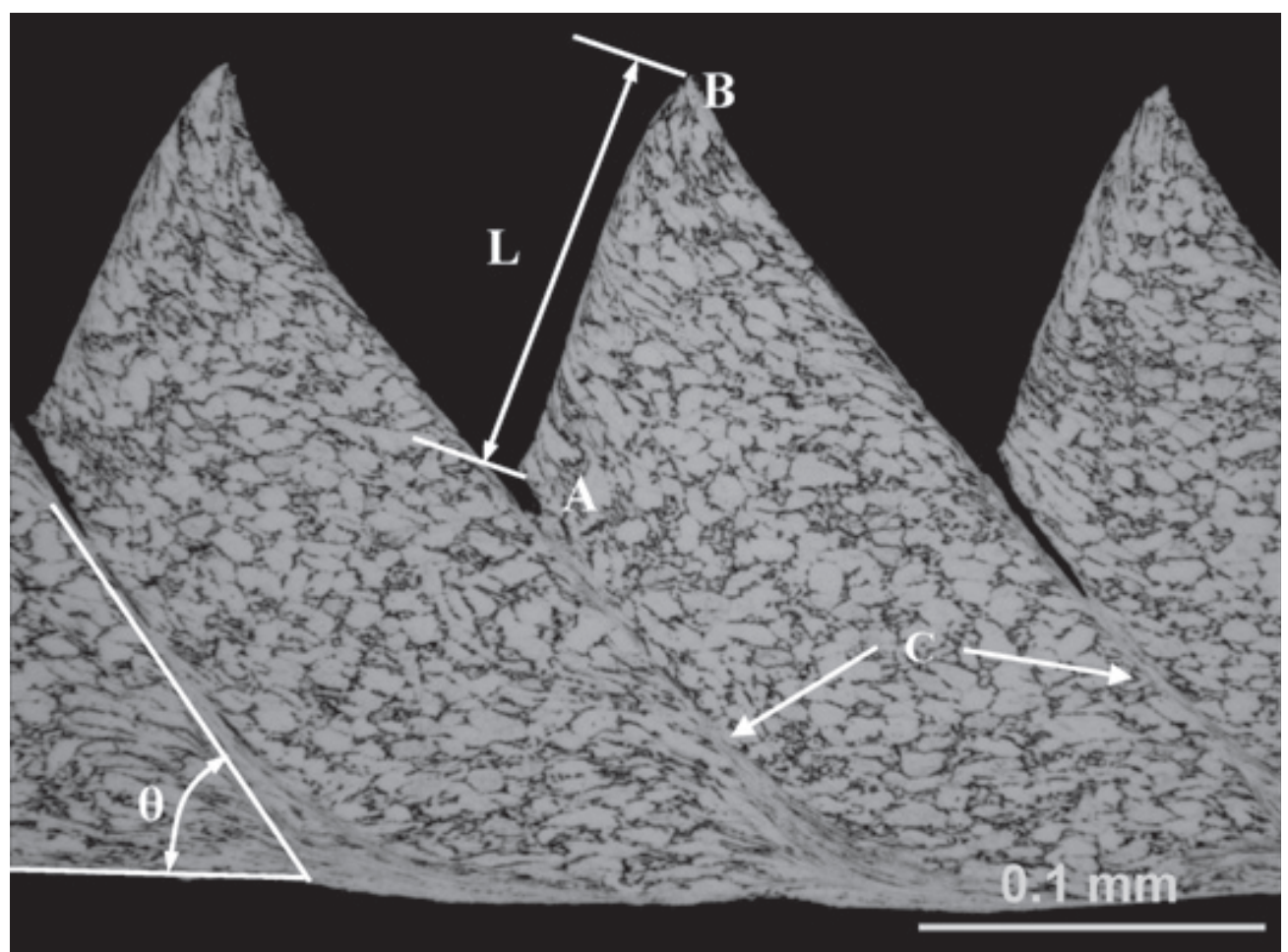

Fig. 1 Cross-section of a typical segmented chip in machining of Ti6Al4V alloy [18]

The segmented chip formation is believed to be due to the growth of cracks $[19,20]$ and adiabatic shear band formation occur from the predominance of strain hardening over thermal softening and the 
difficulty of dislocation motion through the microstructure $[10,13,16]$. The excessive shear localisation and strain hardening are may be due to phase transformation (hexagonal close pack to the body centred cubic) of titanium structure. The temperature can be very high and localised in some areas of workpiece due to low thermal conductivity of Ti-6Al-4V alloy. The transition in crystal structure presumably results primarily from high pressure and temperature which accompanies plastic deformation $[13,15]$. The onset of shear instability in chips is associated with cutting conditions and material properties of the workpiece $[15,21]$. The shear banding frequency increases with the increase of feed rate and decrease of cutting speed. Feed rate has a more significant effect on the shear banding frequency than does the cutting speed, although their effects are in opposite directions [15]. There is critical cutting speed for the 'thermo-plastic' instability (adiabatic shear) to take place in machining Ti-6Al-4V [13,22]. This critical cutting condition varies for different tool-workpiece material combinations [21] and depends on many other parameters such as cutting tool geometry, machine tool stability, etc. For Ti-6A1-4V alloy the saw tooth chips are generated when the product of feed and speed is around 0.004 or above [15]. Semiatin et al., [23] found that the shear localization occurs when the slope of strain- strain rate curve reaches 5 times the strain rate value. The applicability of this criterion was demonstrated to metalworking and metal cutting processes including titanium machining. Hou and Komanduri [24] suggested that the shear localization occurs when stress in the localized region is lower than that in the non-localized region. Gente and Hoffmeister [25] suggested that the shear localization depends on the release of elastic energy and the strain in the localized zone or the cutting speed do not influence during the fracture process.

The underside of saw-tooth chips produced during machining Ti-6Al-4V alloy at high cutting speeds exhibit evidence of ductile fracture through void nucleation, growth and coalescence; the material between the voids necking down to a fine edge, resulting in a very distinctive directional structure [13]. The cracks initiate in the primary zone and propagate towards the free surface at higher cutting speeds (around $600 \mathrm{~m} / \mathrm{min}$ ). Thus chip segments are separated at the free surface but connected at the tool rake face [26]. On the other hand, at lower cutting speeds, the mechanism of failure within the upper region of the primary shear zone appears to be cleavage [13]. It is thought that the adiabatic shear that initiates over the lower region of the primary shear zone does not propagate to the free surface of the workpiece at lower speed [26]. Shear localization results in a cyclic variation of forces (both cutting and thrust) with a significant magnitude variation [21]. The consequent vibration or chatter in the metal cutting process limits the material removal rate and plays an important role in tool wear.

\section{Cutting Tool Materials and Wear}

Different types of cutting tools have been tested for machining different types of titanium alloys [27-31]. Excessive wear which is identified as chemical reaction and adhesion between the tool and work materials occurs in TiN added cermet and the TiC coated tools during machining titanium. The ceramic tool and $\mathrm{CBN}$ tool also experience large groove wear on the flank and rake face. Thus, these tool materials are not suitable for machining titanium alloys. However, only the carbide, binderless $\mathrm{CBN}$, sintered diamond and natural diamond tools show acceptable performance in machining titanium alloy. The sintered diamond tool performs slightly better than carbide tool at low speed but at higher speed both of these tools showed almost similar performance. Tungsten carbide (k10) tool wear increases rapidly after 5 minute cutting at low speed $(100 \mathrm{~m} / \mathrm{min})$ without coolant [27]. However, the wear rate with the water-soluble type coolant is significantly low even after 30 minute cutting. At higher cutting speeds $(198 \mathrm{~m} / \mathrm{min})$, the tool life becomes extremely short. On the other hand, natural diamond tool shows minor wear even after 30 minute cutting at low $(100 \mathrm{~m} / \mathrm{min}$ dry) as well as at higher $(198 \mathrm{~m} / \mathrm{min}$ with coolant) cutting speed. However, severe tool wear is noted with further increase of cutting speed $(300 \mathrm{~m} / \mathrm{min})$ even after cutting few minutes. If the machining is continued longer the soldering material melts and the cutting tip detaches from the holder [27]. The tool life of PCD tool can be achieved as high as 381 minutes with excellent surface finish and 
geometrical accuracy [32]. Kuljanic et al., [32] down milled TiA16V4 titanium with $32 \mathrm{~mm}$ diameter PCD tool at cutting speeds $90,130 \mathrm{~m} / \mathrm{min}$, feed per tooth $125 \mathrm{~mm}$, axial depth of cut $0.3 \mathrm{~mm}$ and radial depth of cut $5 \mathrm{~mm}$. Generally, diffusion and dissolution processes are blamed for damage of PCD tool due to high local temperature [33]. Kuljanic et al., [32] argued that Ti has greater affinity to carbon. Thus, TiC film is formed on the diamond surface due to reaction between the work material and tool material during machining process. This film protects the tool from crater at light cutting.

Binderless $\mathrm{CBN}(\mathrm{BCBN})$ tools do not have any binder to hold the tool material grains, show improved high temperature durability and thermal conductivity [31]. For the similar machining conditions the tool life of a BCBN tool is very similar to that of PCD tools during milling Ti6Al4V [34]. BCBN tools exhibit lower flank wear and sharper cutting edge compare to that of sintered carbide, PCBN and PCD tools during turning of Ti6A12Nb1Ta [35]. During machining workpice material attach to the flank face of the BCBN tool and protects the tool wear for some time. Non-uniform attrition wear wear in the flank is the dominant wear pattern for BCBN tool [36].

Some coatings, such as, TiN (by physical vapour deposition) and $\mathrm{TiCN}+\mathrm{Al}_{2} \mathrm{O}_{3}$ (by chemical vapour deposition) are shown to improve life of carbide tools (milling process) [37]. The both of these two tools exhibit a tool life of $30 \mathrm{~min}$ at the cutting speed of $55 \mathrm{~m} / \mathrm{min}$ and a feed of $0.1 \mathrm{~mm}$ per tooth. TiCN $(3.1 \mu \mathrm{m})$ and AlSiTiN $(3.9 \mu \mathrm{m})$ coatings (by arc evaporation) also show better performances (almost double tool life) at a cutting speed range of $50-130 \mathrm{~m} / \mathrm{min}$ (turning) in wet and MQL condition, compare to the uncoated carbide tools. The nano-crystalline structure with the multilayer architecture, better abrasion resistance and superior adhesion properties of AlSiTiN coating makes it to perform better than TiCN [38]. All coatings may not increase performance, such as, HfC coating. A six micron thick HfC coated tool was seen to wear (in turning process) at about 20 times the rate of the identical uncoated tool [38]. Carbide tools with a larger grain size $(1.0 \mu \mathrm{m})$ shows better resistance to flank wear due to lower solubility of WC in titanium alloys than those with smaller grain size $(0.68 \mu \mathrm{m})$ [37].

The main causes of tool wear for different cutting tools are: coating delamination (coated tool), adhesion, attrition, diffusion, plastic deformation and cracks [29,30,37]. The two possible reasons of coating delamination are: (1) chemical reaction and (2) difference in the thermal expansion coefficient between the coating matrix and the substrate. Adhesion of workpiece material on cutting tool is very common during machining titanium [40]. With the progress of cutting, the welded (due to adhesion) work material on cutting tool is compressed and removed. This also leads to plucking of cutting tool grains which is called attrition. Attrition wear is observed on the rake face as well as flank face. Evidence of diffusion of cobalt and tungsten atoms into the work material was found when machining with coated/uncoated carbide tools at reasonably higher cutting speed. The diffusion process, which is the main problem for machining titanium, comprises element diffusion and chemical reaction between the work piece and the tool. This type of wear is more active at high cutting speeds or when there is a high temperature at the tool-chip interface, and is enhanced by a strong chemical affinity between the workpiece and the cutting tool materials [41]. The extreme temperature, pressure and the intimate contact at tool-chip interface offers a perfect condition for the diffusion of tool material to the workpiece [37]. Ti, Al, and $\mathrm{V}$ of the Ti-6Al-4V alloy are seen to diffuse into the WC (Co binder) tools during machining at higher cutting temperature. Under similar conditions, $\mathrm{W}$ and Co of the WC (Co binder) tool also diffuse into Ti-6Al-4V alloy [29,42]. These change the composition and affect the performance of cutting tool [30]. The diffusion of Co from cutting tool weakens the bonding among carbide grains thus with the progress of machining attrition wear exposes Co from the underneath of newly removed carbide particles. Due to high temperature and stress plastic deformation takes place at cutting edge during machining of titanium. Plastic deformation becomes more sever at higher cutting speed and feed. This is due to the higher cutting temperature and smaller contact at tool-chip interface at high cutting speeds as mention earlier. It is thought that in the region of the highest compressive stress the yield stress in the tool was reduced, which resulted in plastic deformation of the tool [37]. Generally several tool wear mechanism take place simultaneously and those affect one another which deteriorate and weakens the cutting tool and stimulates existing cracks to propagate. Among the above types of tool wear, diffusion and adhesive 
wear are the main mechanism to tool failure [30]. Abrasion is the major wear mechanism that causes of flank wear when machining with carbide tools at lower speed conditions $[12,27,43]$.

The theories (based on chemical dissolution of the tool material) to predict relative tool wear rate or tool wear does not work properly for machining titanium [39]. Turkovich et. al., [39] carefully monitored the wear of polycrystalline diamond tools in turning of Ti $6 \mathrm{~A} 1-4 \mathrm{~V}$ at $61.0 \mathrm{~m} / \mathrm{min}$. An adherent layer of titanium is seen on the rake face from the start of machining. After 15 minutes of cutting, 20 microns of wear was apparent on the rake face at different locations but there were regions with no wear. This kind of scallop appearance wear on the rake face is also seen on the CBN and the coated carbide tools. Uncoated cemented tungsten carbide tools do not show this type of wear when machining Ti $6 \mathrm{~A} 1-4 \mathrm{~V}$, but a more conventional crater wear. The tool failure modes are plastic deformation and brittle fracture, such as, rake face flaking, cracking, chipping and fracturing [28]. At certain cutting conditions titanium (Ti 6A1-4V) adheres to the tool and sliding does not take place at the tool-chip interface. Part of the boundary layer quickly becomes saturated with some tool material which limits the further diffusion of tool materials to chips. Thus, no wear occurs in certain regions on the rake face of some tools. The existence of TiC layer on the surface of the tool indicates the diffusion of carbon through the $\mathrm{TiC}$ layer.

\section{Summary}

The understanding of machining mechanism has progressed significantly but application of this understanding is not yet available. Thus research focus is required to be on how the productivity of titanium alloys machining can be improved with the available understanding. None of the cutting tools available in the market gives expected tool life. Therefore, new cutting tool materials need to be introduced.

\section{References}

[1] J.F. Kahles, M.Field, D. Eylon, F.H. Froes: Journal of Metals, 37(4) (1985), p.27

[2] W.F. Smith, Structure and Properties of Engineering Alloys, McGraw-Hill, New York (1981)

[3] S. Sharma, M. Dograb, N.M. Suri: Int. J. of Machine Tools \& Manufacture, 49 (2009) 435-453.

[4] Geoffrey Boothroyd, Winston A. Knight, Fundamentals of Machining and Machine Tools, third ed, CRC Taylor \& Francis (2005).

[5] H. Zhao, G.C. Barber, Q. Zou: Wear 253 (2002) 957-962.

[6] T.H.C. Childs, K. Maekawa, T. Obikawa, Y. Yamane, Metal Machining Theory and Applications, Butterworth Heinemann, Oxford ( 2001).

[7] D.R. Chichili, K.T. Ramesh, K.J. Hemker: Acta Mater., 46 (1998), p.1025

[8] K.T. Ramesh: Metallurgical and materials transactions A, 33(2002), p. 927

[9] P. Follansbee, G.T. Gray: Metallurgical Transactions A, 20(1989), p. 863

[10] A. Ginting, M. Nouari: Int. J of Machine Tools \& Manufacture, 46 (2006), p. 758

[11] E.O. Ezugwu, Z.M. Wang: J. of Materials Processing Technology, 68 (1997), p. 262

[12] E.O. Ezugwu, J. Bonney, Y. Yamane: J. of Mat. Processing Technology, 134 (2003), p. 233

[13] J. Barry, G. Byrne, D. Lennon: Int. J. of Machine Tools and Manufacture, 41 (2001), p. 1055

[14] J.S. Ahmad, J.A. Bailey: J. of Manuf. Sci. and Eng., Trans. of the ASME, 119(3)(1997), p. 307

[15] A.E. Bayoumi, J.Q. Xie: Materials Science and Engineering A, 190 (1-2) (1995), p. 173

[16] R. Komanduri, B.F.V. Turkovich: Wear, 6 (1981), p. 179 
[17] R. Komanduri: Wear, 76 (1982), p. 15

[18] S. Sun, M. Brandt, M.S. Dargusch: Int. J. of Machine Tools \& Manufacture, 49 (2009), p. 561

[19] A. Vyas, M.C. Shaw: J. of Manuf. Sci. and Eng. Trans. of the ASME, 211(1999), p.163

[20] T. Obikawa, E.Usui: J. of Manuf. Sci. and Eng.-Trans. of the ASME, 118(1996), p. 208

[21] R. Komanduri, Z.-B. Hou: Metallurgical and Materials Transactions, 33A (2002), p. 2995

[22] Z.B. Hou, R. Komanduri: Ann. CIRP, 44 (1) (1995), p. 69

[23] S.L. Semiatin, G.D. Lahoti, S.I. Oh: The Occurrence of Shear Bands in Metalworking, in Material behavior under high stress and ultrahigh loading Rates, Plenum Press, New York, 1983

[24] B.H. Hou, R. Komanduri: Int. J. Mech. Sci., 39/11(1997), p. 1273

[25] A, Gente, H.W. Hoffmeister: Annals of the CIRP, 50/1 (2001), p 49-52

[26] R. Shivpuri, J. Hua, P. Mittal, A.K. Srivastava: CIRP Annals- Manuf. Tech., 51(1)(2002), p. 71

[27] H. Takeyama, A. Murakoshi, S. Motonishi, N. Narutaki: Ann. CIRP, 32 (1) (1983), p. 65-69

[28] C.H.C. Haron, A. Ginting, H. Arshad: J. of Mat. Processing Technology, 185: (2007), p. 77-82.

[29] A. Jawaid, C.H.C. Haron, A. Abdullah: J. of Mat. Processing Technology, 92-93(1999), p. 329

[30] D. Jianxin, L. Yousheng, S. Wenlong: Wear, 265 (2008), p. 1776

[31] M. Rahman, Z.G. Wang, Y.S. Wong: JSME International Journal Series C, 49(1)(2006), p. 11

[32] E. Kuljanic, M. Fioretti, L. Beltrame, F. Miani: CIRP Annals- Manuf. Tech., 47(1) (1998), p. 61

[33] F. Nabhani: Robotics and Computer Integrated Manufacturing, 17: (2001), p. 99

[34] A.R. Zareena: High-speed machining of titanium alloys, Master Thesis, National University of Singapore, Singapore (2002).

[35] K. Hirosaki, K. Shintani, et al.,: JSME International Journal Series C, 47(1) (2004), p. 14

[36] Z.G. Wang, Y.S. Wong, M. Rahman: Int. J. of Machine Tools and Manuf., 45(1)(2005a), p. 105

[37] A. Jawaid, S. Sharif, S. Koksal, Journal of Materials Processing Technology, 99 (2000), p. 266

[38] L. Settineri, M.G. Faga: Machining Science and Technology, 12(2008), p. 158

[39] B.F.V. Turkovich, P.D. Hartung, B.M. Kramer: Annals of the ClRP, 31(1) (1982), p. 75

[40] W. Konig, R. Fritsch, D. Kammermeier, Surface Coatings Technology, 49(1991), p. 316

[41] M.N. Molinari: Wear, 252 (2002), p. 135

[42] Y. Su, N. He, L. Li, X.L. Li: Wear, 261 (7-8)(2006), p. 760

[43] P.A. Dearnly, A.N. Grearson: Material Science and Technology, 2 (1986), p. 47 